\title{
UNA EXTRAÑA PROSA ECLÉCTICA DE PEDRO MANUEL XIMÉNEZ DE URREA: LA BATALLA DE AMORES
}

\section{INTRODUCCIÓN}

En el Cancionero de todas las obras de don Pedro Manuel de Urrea (Juan de Villaquirán, Toledo, 1516) figura toda suerte de géneros literarios: poesías (romances, canciones y villancicos la mayoría de ellas), breves piezas teatrales, cartas a familiares, su "novela" $P e$ nitencia de amor, y unas breves prosas. Los títulos de éstas parecen indicar una cierta unidad de intereses - Jardín de hermosura (la más larga de ellas: ff. xxxii-xxxviij), Fiestas de amor, Sepoltura de amor, Rueda de peregrinación y Batalla de amores-, pero erraría quien creyese que cuatro de ellas versan sobre el amor cortés o mundano, y sólo una, la Rueda, sobre algún tema religioso. Efectivamente, las que parecen ser seculares también incluyen consejos y admoniciones que pretenden poner a salvo el alma del lector. Urrea describe cómo él mismo se encuentra ante una visión o escena, cada cual basada en la alegoría o bordando en ella; para preservarse incorrupto por los malhechores o las tentaciones que le rodean y acosan, se ha apartado del mundo. Éste es perverso, él mismo se salvará e increpa o sugiere a sus lectores que sigan la indicada vía salutífera.

La preocupación por este tema está bastante difundida en toda la obra del segundón aragonés; por el momento válgannos como ejemplos dos citas más, primero una poética de "Otra obra suya llamada Peligro del mundo, dirigida a la Condessa su madre": "También desalabo la mala intención / del que sólo ama lo que él se posee, / y todo lo otro que en otros él vee, / querría ser ciego con su gran passión. / Por no poder ver la deleytación / por iniquidad en poder ageno, léste lieua brasas en su propio seno; / de ageno deleyte pena el coraçón" (f. xlv ro).

En su Obra llamada Casa de sabiduría, el autor está alejándose 
cuando por casualidad se tropieza con Amor mismo:

Conosciendo los engaños y peligros que en esta vida se hallan y se siguen, no tanto con miedo de ser engañado como con temor de engañar, recelando más el peligro dell alma que el daño del cuerpo, acordé vn verano, en $e$ l agradable mes de mayo quando la gente siguiendo el buen tiempo procuran el malo, y como salen del triste inuierno siguen ell alegría hasta llegar a la tristura, yo, por huyr de los dulces plazeres que traen amargos pezares [sic], fuyme a vna huerta. Y auiendo poco tiempo que en ella estaua, vi entrar vn mancebo que vna vez me parescía viejo y otra vez moço, el qual traya vn arco de saeta en la mano y dos aljabas, la vna llena de saetas doradas, y en la otra, de plomo; y avnque en la manera venía ferosce, en el rostro venía humilde (f. vij $\mathrm{r}^{\circ}$ ).

Como en la Batalla, también en esta obra encontramos una mezcla de temas religiosos (un desfile de los siete pecados, cada cual con su rótulo) y un bando de viejos sabios ("Dante, Petrarca, Uirgilio, Homero, Juuenal, Terencio, Ouidio, Persio, Ualerio, Horacio, Séneca, Salustio" [f. viij r r ]) que aconsejan en contra del amor.

¿Misantropía o religiosidad? De aquélla tenemos bastantes pruebas textuales difundidas en sus obras ${ }^{1}$, pero lo mismo podemos decir de ésta. No nos es posible dictar una respuesta incontrovertible, pues tan poco sabemos del hombre mismo. La tabla del Cancionero, sin embargo, lleva una frase que pica la curiosidad: "Acabado todo lo que en él [es decir, el Cancionero] hasta veynte y cinco años" (f. $1 \mathrm{v}^{\circ}$ ). Empleo lo dicho como punto de partida para una hipótesis.

Todas estas obras son de la juventud y primera madurez de Urrea. Sus poemas y cartas dan a entender que está malhumorado con su familia, su indigencia, su ruda herencia en las faldas del Moncayo, sus pleitos para aumentar su herencia; unos cuantos datos biográficos parecen indicar una personalidad querellosa. A pesar de ser adepto a la poesía del amor cortés - que puede ser sólo ademán creador - frecuentemente rechaza los gustos y placeres del mundo a favor de la redención personal y la salvación del alma. Varias veces explica que nunca ha querido que sus creaciones lleguen a ser expuestas fuera del círculo familiar, si no

1 Para más datos sobre la personalidad de Urrea y su casi inexistente biografía, remito al lector a mi edición de Penitencia de amor, de aparición hacia principios de 1990 en la serie Exeter Hispanic Texts publicada por la University of Exeter (Inglaterra). 
de su propio escritorio, como explica en una carta a doña Catalina de Urrea, su hermana: "he yo siempre procurado, que cosas mías en poder ageno no se hallen" (f. iiij $\mathrm{r}^{0}$ ). Que sepamos, la única obra suya publicada después del Cancionero de 1516 fue la Peregrinación a Iherusalém, "o sea Peregrinacion a Jerusalen, Roma y Santiago, dividida en tres libros y los libros en capítulos, y que fué impresa en Burgos en 1523"', está perdida. Creo que todos estos datos justifican la idea propuesta por Roger Boase, según el cual Urrea se hizo religioso en plena madurez ${ }^{3}$. La misantropía habría podido ser fruto de ser segundón - le nació una "secreta amargura" por esto, según Eugenio Asensio 4 . Es posible que tal sentimiento no haya durado mucho, y haya sido sustituido por la religiosidad. Esta inclinación a la religión - ¿imodo de escape? - es clara, aunque sólo esporádicamente se explicita en sus páginas: el efecto es producir obras que extrañan por su heterogeneidad.

Ejemplo de esto es la Batalla de Amores, inédita hasta hoy. A continuación se ofrece una transcripción con resolución de abreviaturas, y división de frases y puntuación modernas.

\title{
Robert L. Hathaway \\ Colgate University
}

\author{
[f. $\left.x x i v v^{\circ} a\right]$ \\ Batalla De amores \\ compuesta por don Pedro Manuel de Urrea
}

Reposando mi entendimiento fatigado de pensar en las muchas discordias que por tantas maneras passan, y cómo cada qual no entiende ni piensa sino en dar remedio a ssí mismo, y todos o los más entienden en prouar engaño; estando yo dudando en mí mismo adónde auía más peligro, en la soledad o en la compañía, hallé (si yo no conté mal) que la soledad, avnque trae pensamientos que a los tristes quando están solos haze desesperar, la compañía haze y causa mayores yerros. Porque es-

${ }^{2}$ Martín Villar (ed.), Cancionero de D. Pedro Manuel Ximenez de Urrea, publicado por la Excma. Diputacion de Zaragoza, teniendo á la vista la unica y hoy rarisima edicion que se hizo en Logroño en 1513, Zaragoza, 1878, p.vii.

3 “Pedro Manuel Ximénez de Urrea (1486-c.1530). A biographical inquiry", $I, 9$ (1977), p. 44.

${ }^{4}$ En su edición del teatro de Urrea, Églogas dramáticas y poesias desconocidas, Imprenta de C. Bermejo, Madrid, 1950, p.xvii. 
tando solo tiene hombre su sola condición, y acompañado a de seguir las agenas adonde, por fmerça oyendo dezir mal de los absentes, algunos por contentar ayudan, diziendo algunas vezes lo que les pesa dezir; y por no tener señorío la condición sobre la lengua, dizen mal de quien quieren bien. Y avnque mi condición de todo esto se apartaua quise quitarme de inconuinientes ${ }^{1}$. Y assí por esto como por otras cosas, fue my parescer yrme solo por vn monte que, según estaua de flores, mucho mejor que huerta me parescía; adonde topé con vn hermitaño el qual me dixo que venía espantado de lo que auía visto en vn llano, estando él en vn alto de la qual cumbre se veya todo. Y él, como por estar solo no osó estar allí, comigo boluió allá adonde subimos los dos. El qual me dixo y rogó que, pues yo auía visto de aquello ${ }^{2}$ más que él, que le pagasse el mostrarme el lugar con dezirle lo que era. Dixo que vería $[f$. $\left.\begin{array}{lll}x x i v & v^{\circ} b\end{array}\right]$ vna batalla de lo qual él hallaua saber poco porque todo su tiempo auía gastado en aprender theología, cosa bien differente de aquello.

Y estando assí los dos solos hablando, yo le dixe qué batalla era aquélla, porque yo estaua muy triste de oyr tantas que entre christianos se dauan, y que me dixesse si esta batalla era contra $r$ oros. Porque yo cierto estaua espantado pensando en la mucha sabiduría de Dios y el mucho suffrimiento que tenía, que bien nos mostraua auerse puesto en la Cruz según lo que agora suffría, avnque con otras razones de Él mismo

1 Ya se ha comentado este deseo de alejarse de los males mundanales; es el que también siente Mingo en la breve pieza Nave de seguridad: " $\mathrm{O}$ falso biuir de mundo enemigo! / $\mathrm{O}$ graues engaños de gente peruersa! / $\mathrm{O}$ fuertes cautelas de orden diuersa!" (f. xciij v"); en vez de seguir sufriéndolos, el pastor decide partirse como criado al servicio de un marinero. En fin, no importa el género de sus obras - poesía, prosa, teatro- Urrea solía infundir muchas de ellas con este sentimiento angustiado. ¿Habría sido por catarsis personal? Visto lo poquísimo que sabemos de su vida, resulta imposible contestar la pregunta.

2 Se referirá "aquello" a lo mundanal; a pesar de resultar alegórica, la confrontación que los dos presenciarán desde lejos más tiene que ver con el mundo cotidiano que con el celestial tan apetecido del ermitaño. Como se ve en la frase siguiente, la teología compagina mal con el amor humano. El encuentro casual con quien luego le explicará algún caso que importa a la salud del poeta es también la técnica que emplea Urrea para introducir una conversación con Amor en el poema "Otra obra suya llamada Desesperación de amor". El poeta acaba de sacar a tierra a un náufrago, pero Amor interrumpe bajando por una sierra y le manda que no tenga más que hacer con él, pues sufre un justo castigo: "De la torre de la fe / hasta el suelo de uentura / cayó por su desuentura; / por esto le condené" (f. xxiij v"). La primera estrofa de la poesía demuestra claramente que la obra pertenece tanto como la Batalla al género de los viajes imaginados: "Destar pensando en amores / vy mis razones tan ciegas / que me fuy por vna vegas / sin gana de ver las flores. / Y con continos temores / llegué junto cabe vn río / de vn pensar qual es el mío / de lágrimas de amadores" (f. xxiij r ${ }^{n}$ ). 
se prouaua ver los buenos, quán pocos eran, y los malos, quán prósperos andauan; y esto no solamente entre nosotros mas avn en los agenos. Que se auía perdido tanta tierra, en leuante la metad del mundo o la mayor parte dél por batallas en poder de paganos, enemigos de su sanctíssima ley. Él me dixo que no me marauillase que los cristianos vuiéssemos rescebido algún daño, que agora sabía yo que a los que dizen las verdades, que les quiebran las cabeças, y que cada qual seguía los passos según su ley: los judíos, por auer hecho aquella iniquidad con el Messías, quedauan avn puercos y tratadores assí de nuestra muerte como de la cristiano [sic]. Y nosotros, como tenemos ley humilde, auemos de seguyr humildad. Los moros, como la tienen tomada por armas, andan siempre en guerra; que allá en su renegada tierra toman los niños y los hazen por fuerça moros porque de pequeños tomen mejor aquella inica [sic] seta, y luego los ponen en armas; uassí [sie] $]^{3}$ como acá les mostramos rezar, les muestran allá com [f.xxv $\left.r^{\prime \prime} a\right]$ batir; mas aquel mucho coraçón no es de buena ley porque siempre que hombre está con yra, está animoso esforçado. Pues Dios no quiere yra ni esfuerço sino humanidad y mansedumbre; assí como nos dixo, Exemplum meum do vobis, que nos da su exemplo no solamente que seamos humildes, mas avn que padescamos acá tormentos como Él padesció. Y que cada capitán a de llenar la gente según su bandera y que la cruz nos significa tormento; que con fatiga nos auemos de saluar, que los deleytes que son vicios nos están vedados. Y más me dixo este hermitaño, que pues que la mayor parte del mundo sigue los vicios que no me marauille yo que sean más los malos que los buenos, porque siempre lo auía hecho Dios assí. Que assí como los moros tienen mucha [sic] más tierra que nosotros siendo ellos malos, que assí también, en el tiempo que los jadíos tenían sanctíssima ley, estauan los gentiles más prósperos que ellos; y otra gente, sin tener buena ley tenían mucha tierra. Que sobre esto auía tantas razones para prouar que no va la virtud ni la verdad en los más, que por escusar prolixidad no lo dezía. Díxele yo que, pues tan sabio era, que me dixesse el engaño de los moros en las cosas que el affición los tenía ciegos. Y que, pues yo sabía que la ley dellos era tomada por el mundo por ser viciosa, que me contasse algo sobrello ${ }^{4}$.

${ }^{3}$ Debe leerse "y assí"; la $u$ sería error del cajista.

${ }^{4}$ Eso de "vna batalla" queda ya olvidado. ¿Estarán en camino a verla, o es que el término "batalla" ahora se presta a la lucha de castas, de teologías contrastadas, siempre en denigración de las no católicas? Así el verdadero amor de Dios, el catolicismo, debe vencer sobre las herejías, también sobre el vero amor que, en su propia esfera, debe ganar el premio, y no el amor impuro, victoria que pronto se ilustrará con los famosos enamorados. Hay como una línea divisoria, más o menos al final del folio xxxvj v"b, entre dos batallas. Aunque la segunda es la que anuncia Urrea de antemano (y será la que provee el título), porque la de la religión precede, y más importante aún, la sigue y contrarresta, se deduce fácilmente la primacía; véase la última frase de la obra. 
Díxome luego assí: "Los moros contradizen nuestra ley, en lo qual muestran ser la suya falsa, porque ninguna ley no puede contradezirse sino cumplirse y affirmase [sic], como sea cosa dada por Dios, el qual no sea mudable; no puede porque no quiere hazer cosas variables. Mas porque veáys dónde está el engaño, los judíos, como quedaron offendidos en la passión de Nuestro Saluador, con la biueza y agudeza que ellos tienen y con muchos males que en nosotros moran (como avn agora paresce que andan haziendo harto daño y bien secreto en la christiandad, queriendo nosotros ligar con ellos), quando vieron que por fuerça no nos pudieron vencer, prouaron con maña, la qual reyna mucho en ellos 5 porque siempre hazen sus cosas en consejo todos juntos. Y desta manera no me marauillo yo auer to $\left[f . x x v r^{\circ} b\right]$ mado vengança ellos de nosotros, mas de auer cristianos en el mundo según los males ay en todas las prouincias de la tierra. Y assí todos ellos puestos en consejo, como ellos andauan enbueltos con nosotros y nosotros con ellos por casamientos y erencias, y oor otras muchas maneras ${ }^{6}$, viniendo algún tienıo a tener alguna fuerça por causa nuestra sobre nosotros con la mucha pompa que ellos han tenido y tienen, estando injuriados de estar debaxo de nuestra ley, acordaron de hazer ley que pareciesse otra y que fuesse la misma, queriendo creer algo la venida del Mesías. Y por no otorgar que ellos le hauían crucificado, que fue esto causa de entrar pocos en nuestra fe, hizieron con falsas opiniones esta seta de los moros, como claramente paresce. Que todo quanto tienen es de la ley vieja, como son los nombres, que se llaman Yucé ${ }^{7}$ como los judíos, y en todas las otras cosas, que se circuncidan como los judíos y no comen puerco. Y estas cosas, como sean por nosotros reprouadas y vedadas y cumplidas, no pueden tornar a rebibar. Y más el sacrificio que hazen de Abraham, no entienden que es ley de figura que se cumplió con la nuestra, porque Dios mandó a Abraham que sacrificasse a su hijo, que quería dezir que Dios auía de sacrificar al suyo que era Christo ${ }^{8}$ Y $\mathrm{Y}$ assí llamamos a Christo Cordero de Dios como Abraham le paresció allí vn cordero. Assí vino Christo como cordero a ser puesto en la Cruz; y por esto vn vellaco soldado

${ }^{5}$ El leve antisemitismo se ilustra en los clisés, aquí con el judío mañoso y por esto despreciado; debemos preguntarnos cuán sincero es el ataque, pues está atenuado por lo que sigue en el texto.

${ }^{6}$ Asensio cita esta frase al expresar su sospecha de que Urrea hubiera tenido sangre judía, como la tenía su esposa, doña María de Sesé (Églogas, p. xliii).

${ }^{7}$ En cuanto a los nombres, profetiza Urrea en su poesía "Contra la seta mahomética"': "Pues, falso Mahoma, mira que al revés / mudarán los nombres de tu Alcorán: / a Mahoma, Pedro, y a Muça, Juan; / todos tus hechos darán al través" (f. xlix v ${ }^{\circ}$ ).

${ }^{8}$ Urrea comenta la inescrutabilidad de esto en "Otras suyas contemplando en la Passión de Nuestro Señor": "O mysterio tan profundo, / que la humanidad no alcança / en esta baxa balança / verte, Dios, puesto en el mundo / por cumplir nuestra esperança" (f. vj $\mathrm{r}^{0}$ ). 
renegaua de los lobos porque no se auían comido a Jesuchristo quando era cordero, y de los peces porque no comieron los pies de Sant Christóual quando passaua a Cristo por ell agua. Y assí con eregías donosas se destruye el mundo y çúffrelo Dios todo y da el pago allá. Y según lo que Dios haze, lo que acá se toma allá se paga.

"Mas veréys otra cosa en esta falsa ceta $[$ sic] de los moros", me dixo el hermitaño; "haze seruicio a Dios".

"Hermitaño santo", le dixo [sic] yo, "en dezir lo malo, ¿qué de su deformada ley sentís?",

Dixo él: "Estos engañados moros dizen que Cristo fue hecho por el resollo de Dios en Nuestra Señora. Pues claro está que qualquiere que haga vn hijo en vna muger, aora sea por resollo y de qual[f. $\left.x x v v^{\circ} a\right]$ quier otra manera, será su hijo por ser engendrado - que toda cosa engendrada se llama hijo- porque luego que salga por su resollo es cosa propia ajuntada en su propio ser. Porque no puede aver en mí cosa que no sea yo. Hazemos a Christo otra persona porque entre el que da y el que rescibe a de aver apartamiento; y como Christo vino a la tierra es otra persona, como se muestra en sus mismas palabras y en el Credo de sus Apóstoles y en el címbolo [sic] santíssimo de Atanasio. $\mathrm{Y}$ en el Euangelio de Sant Juan, Yn principio erat verbum, que quiere dezir Cristo que era cabe Dios et Deus erat verbuz [sic], Dios era Cristo porque a Cristo llamamos palabra de su Padre. Como avn el moro lo dize, que salió como palabra por resollo, pues el Espíritu Sancto, el ángel lo dixo a Nuestra Señora que el Espíritu Santo vernía en ella. Infinitas razones ay para prouar ser Dios Trinidad y todas dichas por Dios mismo, diziendo a los judíos por figuras y a nosotros claro. De manera que los judíos pecan de malacia [sic] y los moros de ignorancia; porque, según las burlas que tienen en su escriptura de Alcorán, paresce propia poesía, y por esto se dan ellos a ser físicos por no ver su teología engañosa. Y assí que los vnos tienen ley falta y los otros falsa ${ }^{9}$. Y como Cristo fue el Saluador miguno $[s i c]$ se puede saluar en otro nombre".

Díxele yo luego, "Hermitaño de buena vida, yo tengo bien conoscido ser palabras de Dios las vuesttras; y veo que pues que Cristo fue el Saluador, no auía necessidad que otro viniesse si las malicias y opinio-

${ }^{9}$ ¿Cuál se le habría ocurrido a Urrea primero, la discusión misma o el juego de palabras como resumen? De todos modos, aquí trata del mismo tema de la "Obra trobada por don Pedro Manuel de Urrea contra la seta mahomética": "La ley que dexaste con luna que muda, / va tan aparte de aquél que consiente / que no sé qué verso muy bien te lo cuente, / pues que tú vees de Dios ser desnuda. / Tu guerra dichosa, tu escriptura cruda, / hizo gran pueblo de Dios enemigo; / que aquél que pensauas estaua contigo, / ni a muertos perdona ni a biuos ayuda"' (f. xlviij $v^{\circ}$ ). En otros versos repite la idea de la ficción que representa el Corán: "heziste vna obra de falso poeta", pero pronto desaparecerá: " No está muy lexos la perdición / de vuestro Alcorán que miente a lo largo" (f. xlix r ${ }^{\circ}$. 
nes del mundo lo quisieran. Pues que si dezimos que Cristo fue embiado hablamos quanto a la humanidad, que quanto a la diuinidad no fue embiado sino que vino como dize Sant Juan, In propria venit. Porque Cristo es ressollo de Dios, alma de Dios que es Dios; y assí mirando su nascimiento y su vida y su muerte, con otras muchas cosas que en Él uvo, quien por Él no se guía no lieua buena claridad'.

Respondióme: "Pues que veo que holgáys de lo que oys, yo quiero más largamente hablar de la verdad en nuestra ley. Para conoscimiento de la verdad es menestar [sic] que se crea que dixo Dios en el testamento viejo que cumpliría aquella ley y que vernía el Saluador. Pues luego que nosotros dezimos que es venido ya $\left[f . x x v v^{\prime \prime} b\right]$ somos saluos, porque la palabra y offrescimiento de Dios no puede mentir. Pues luego que somos saluos qualquiera que se aparta de aquí se pierde. Viendo a Cristo en cuerpo y en alma al costado de su padre, y allí junto en cuerpo y alma a Nuestra Señora, ¿qué se busca más? ¿Qué caso se haze de la madre de Mahoma? Ella no concibió por el espíritu de Dios, ni quedó virgen ni parió sin dolor. Pues Mahoma, que está su cuerpo en el ayre ${ }^{10}$, está por la virtud que la caramida tiene sobrel azero, lo qual avnque no estuuiesse el cuerpo de Mahoma allí, lo haría. Y cierto el cuerpo de Mahoma fuera llenado con el alma a infierno sino que yo creo que por dos cosas no quiso Dios: la primera, porque no hizo Él tanto daño como otros, judíos y letrados ${ }^{11}$, en aquella opinión hizieron; lo segundo [sic], porque no pensassen algunos que después vinieron que auía sido leuado a parayso.

"Mas si bien se mira todo quanto ellos tienen es del testamento viejo, çúffrelos Dios como çuffre a los judíos que lo crucificaron. Y es muy cierto que si no por el artículo que los moros creen, que fue Cristo engendrado, ya ellos fueran destruydos. Pero los moros se pueden llamar malos christianos o buenos judíos. Todos quantos rezan oras las rezan por Cristo; y los moros y los judíos, sino que no lo entienden, rézanse maytines porque nasció Cristo aquella ora prima. Porque fue presentado delante Pilato, a ora de tercia fue desnudo y atado en vna coluna. A sexta fue puesto en la Cruz; a nona expiró. A bísperas fue baxado en la Cruz y a completas puesto en el sepulchro ${ }^{12}$. De manera que todos quantos

${ }^{10}$ Ignoro la fuente de esta pregunta.

${ }^{11}$ Imprimo aparte en yuxtaposición los dos grupos, los unos que atacan la religión católica, los otros - acaso cristianos ellos mismos- que la minan con sus nimias pesquisas, así para baratear la fe en la Inmaculada.

${ }^{12}$ La explicación del simbolismo de las horas canónicas, si bien parece imaginativa, puede ser tradicional. Traduzco a P. SAlmon en el New Catholic Dictionary, s.v. Divine Office, Roman: "la Iglesia fijó las horas de oraciones que manifiestan la aspiración de alabar a Dios continuamente, haciendo merced del día entero como orientación hacia Él. Las palabras del salmista, "Siete veces al día te alabon (Ps 118.164), inspiraron el desarrollo de las horas. [ ...] Muy temprano en la Iglesia, el recuerdo de un momento de la Pasión fue engarzado con cada una de estas horas; en algunos países, a ellas se añadió el 
rezan, rezan por Cristo porque fue en Él lo que no fue en otro ninguno. Y si sobre esto dixesse yo lo que podría dezir, no estaríades vos tanto en este monte como yo hablaría.

"Mas miremos hazia allá, que me paresce que viene la gente".

Yo le dixe, "Por cierto, mucho me plaze [sic], sancto hermitaño, las santas palabras que me auéys dicho, porque yo quando por aquí vine, venía ya con pensamiento apartado de las cosas del mundo. Mas dezidme", dixe yo, "¿qué gente a de ser ésta?"13

Él me dixo, "Según yo he sabido, aquí se a de dar vna batalla que se llama Batalla de amores. Y por ser cosa apartada de nuestra condición podremos verla de lexos".

Y assí estando los [f. xxyj $\left.r^{\prime \prime} a\right]$ dos, vino llegando la gente a dos partes. Yo rogué al hermitaño que nos alleguássemos [sic] más cerca porque pudiéssemos ver mejor. Pusímonos en parte que estuuimos sin peligro y con vista para poder muy bien ver todo lo que passó. Vino por la vna parte vn tropel de caualleros sin rey de armas ni vandera; y según la orden lleuauan, bien parescía que querían pelear como hombres que sabían poco de guerra, porque dexauan los peones atrás y querían pelear los de cauallo primero, que era cosa para ser presto desbaratados. Y como ellos conoscían que no lleuauan regla ni ordenança ninguna, yuan todos diziendo como por apellido todos juntos y a altas bozes diziendo desta manera:

I Todo deseo es sin orden porque ciega el affición los ojos de la razón ${ }^{14}$.

Por la otra parte venía vn mancebo con vna flecha, que en esto conoscí que era el dios de amor, el qual traya vna vandera de raso pardo con vnas letras de carmesí que dezían:

\section{Tengo ya tanto vencido tan subjeto a mi querer que no hallo a quién vencer ${ }^{15}$.}

Luego cabe él venían muchas damas vestidas de colores, cada vna de recuerdo de las grandes etapas de la historia de la salvación" (McGraw-Hill, New York, 1967, t. 4, p. 918).

${ }^{13}$ La vuelta a la batalla anunciada es tan abrupta como la partida.

14 La descripción facilita claramente la visión de una tropa desordenada, sin mando ni plan; los versos nos hacen creer que Urrea la creó conscientemente como una representación física de la sinrazón (los ojos cegados) infundida en los hombres por Amor ("el afficción").

${ }^{15} \mathrm{La}$ vanagloria de Amor es un tópico muy difundido en el Renacimiento español; véanse por ejemplos consabidos el Diálogo entre el Amor y un viejo (¿Rodrigo de Cota?) y la Representación de Amor de Juan del Encina. 
su manera; y según yo pude comprehender viendo a los caualleros, yuan vestidos de la mesma manera, que mostrauan por las colores (avnque fuessen corriendo vnos a otros) conocerse. Yuan todas las damas a cauallo en hacas francesas y echauan de las manos sendos papeles a manera de justadores con vnas letras que dezían:

I Sin hazer arma vencemos a los que llaman vffanos vencidos de nuestras manos.

Después destas damas venía muy atrás Caba, aquella por quien se auía perdi $\left[f\right.$. xxvj $\left.r^{\circ} b\right]$ do España; que viendo aquella batalla se le acordaua de las muchas que por su causa se mataron, y de muy triste yua sola. La qual lleuaua vna letra que dezía:

I Muy maldita mi hermosura, pues mi amor causó tanto desamor.

Dos caualleros acordaron de hazer vandera y mostraron vna azul con vnas letras blancas que dezían:

\author{
I Nunca será esta bandera \\ bien ganada \\ hasta que sea tomada.
}

Estando ya puestos todos en el campo que se llamaua Desconoscimiento, embiaron los caualleros al dios de amor vn rey de armas, el qual lleuaua por armas vnas llaues y, escrito [sic] en vn papel que dio a Cupido, el dios de amor, vna letra que dezía:

I Mándanos abrir con éssas la presión que aquí se halla captiuos sin dar batalla.

Vyendo el dios de amor que hazían vn [sic] manera de obidiencia, embióles su rey de armas, embiándoles a dezir que saliesse vno dellos para hablar con él, y más que esto vn escrito que dezía:

9 Con esfuerço no vengáys contra nuestro dios y rey, que no lo manda la ley.

Salió vn cauallero, como el dios de amor auía mandado, a hablar con él, el qual haziendo de lexos su acatamiento deuido, siendo su cortesía por el dios de amor bien tomada, luego en llegando le començó a dezir el dios de amor desta manera: 


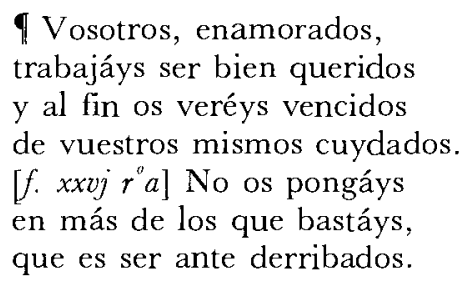

El cauallero, oyendo palabras que tan fuertes le parescían, quedó algo turbado y enmudescido; mas como era escogido entre los otros, avnque las tristes razones le dieron turbación, los alegres desseos causaron osadía. Por lo qual pudo responder por los mismos consonantes desta manera:

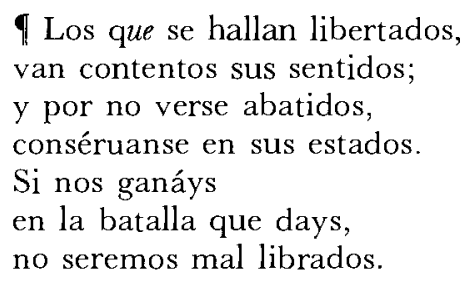

Acordaron los caualleros de dar la batalla y tomar aquellas señoras por fuerça, y viendo que sólo el dios de amor los detenía, que no deuían tener miedo a vno solo. Mas como aquél tuuiesse tal virtud que, por ser su dios, pudiesse más que ellos, tomó el arco en la mano y sus saetas y començó a tirar con tal priessa (como es arma que no a menester mucho tiempo) hirió los vnos y los otros; cayeron, que no tenían fuerça para venir contra él. De manera que allí fueron todos heridos.

Y y $[s i c]$ el dios de amor se boluió hazia las damas y les dixo que aguardassen allí. Y él llegó a los caualleros, y por conoscerlos alẹóles las vistas de los almetes. Y vio luego a Virgilio, el qual estaua muy herido, y díxole el dios de amor desta manera:

$$
\begin{aligned}
& \text { ¿No os bastaua estar colgado } \\
& \text { en el cesto, } \\
& \text { que avn queréys veros en esto? }
\end{aligned}
$$

A otro alçó luego la vista y vio que era Petrarcha, el qual por auer sido del yglesia mostraua estar algo empachado por andar con armas, avnque su mucho saber lo dissimulaua, andando por esconder el [f. $\left.x x v j v^{\circ} b\right]$ rostro en el almete. Mas el dios de amor, alẹándole la vista, conoscióle y díxole assí:

I Madama Laura os hirió, y según es ella hermosa os es la vida dañosa. 
Llegó luego a otro cauallero y alẹándole la vista vio que era César, el qual con rostro de denuedo estuuo esperando lo que le diría, y de manera que avnque se veya derribado, no conoscía ser vencido hasta que el dios de amor, como yua dando a cada qual su aconuerto, llegó dixiéndole estas palabras:

I Vos morys por el [sic] Cleopatra; ¿dónde quexarnos podéys, pues es ella qual vos veys?

Ujo luego a Salamón muy caydo y fatigado, que como auía sido su fuerça más en el ingenio que en la persona, tanto sentía más el vencimiento, porque el cuerpo conoscía el trabajo y el sentido el enojo; mas el dios de amor llegó a él en conosciéndole y díxole assí:

$$
\begin{aligned}
& \text { I La gentil que fue gentil } \\
& \text { hizo vuestro seso feo; } \\
& \text { más que el saber fue el desseo. }
\end{aligned}
$$

Passando adelante topó con Ypólito y vio que estaua mirando hazia la gente que atrás quedaua, como que quería que le socorriessen; mas como su esperança no podía tener buen fin, uiendo ya tan cerca de sí al dios de amor, acordó escuchar y oyr de buena gana estas palabras que le dixo:

$$
\begin{aligned}
& \text { I Fedra os paresció también [sic] } \\
& \text { que avnque estáys tan mal herido } \\
& \text { no os sentís arepentido [sic]. }
\end{aligned}
$$

Andando assí llegó a uer a Eneas, al qual halló no tan triste como a los otros; y que le paresció que no rescibió alegría en verle. De manera que no fue menester el dios de amor $\left[f . x x i j r^{\circ} a\right]$ alçarle la vista para conoscerle; que él mismo descubrió el rostro y se dio a conoscer, oyendo con entera voluntad estas palabras que le dixo:

I Dido es la que os ha dado la herida que tenéys; ved vos si la merecéys.

Estos seys heridos, como son principales, passaron delante de los otros ${ }^{16}$, por lo qual fueron más presto catiuos; mas por esto no queda que no estuuiessen otros muchos en este número de la batalla. Éstos fueron heridos de la propia mano de Amor y los otros temorizados quedaron

${ }^{16}$ Éstos, los seis "principales" y "capitanes de los otros", habrían formado la vanguardia; recuérdese el orden de batalla, los caballeros delante de los peones. 
vencidos. No se habla aquí de otros sino destos seys, por ser estos capitanes de los otros, a los quales el mucho número de los otros dio lugar que éstos por ellos hablassen y hiziessen todo aquello que a ellos paresciesse ser conuiniente para la batalla, el daño y espanto de la qual tocaua a todos ygualmente. Y ellos, viendo que otros ningunos no se avían de señalar en esto sino ellos, acordaron responder al Amor. Y porque Salamón era así el más sabio en el saber como el más noble en la sangre, hizieron que hablasse él por todos, dizéndole [sic] que ellos dauan a él lo que los otros hauían dado a ellos: que él hablase y respondiesse aquello que su mucho saber y discrición hallaua que hazer se deuía. El qual otorgando esto, dixo así:

I Dios de amor, gran dios de amor, todos esto [sic] que aquí estamos, todos la obidencia damos teniéndote por señor; no vses de más rigor.

Ruego a tu persona amada nos lleues a tu posada a darnos algún fauor.

Quando en estas razones vio el dios de amor que todos con mucha obidiencia fe ponían en su poder, como es $\left[f . x x x v i j r^{*} b\right]$ mucho de grandeza perdonar a quien haze obidiencia, assí como es de justiciero castigar a quien tiene ingratitud, acordó lleuarlos a su posada assí como auía sido rogado. Y para dezirles esto respondióles por sus mismos consonantes, diziéndoles assí:

\footnotetext{
I Pues que soys merescedor de lleuaros donde holgamos, yo soy contento que vamos do no andéys alderredor. $\mathrm{Y}$ perded todo temor, que con vida descansada estaréys esta jornada, pues que soys buen amador.
}

De allí fueron todos juntos y nosotros siguiéndolos hasta el aposentamiento del dios de amor. Y llegados a él vímosle todo hecho de azul ${ }^{17}$, que en todo él no auía otra cosa que fuesse de otro color saluo que este azul; auía vno claro y otro escuro, y esto estaua labrado de manera que sigmificaua muchas cosas. Lo más de lo azul era escuro, señido [sic] todo alderredor de piedra blanca con letras que dezían:

${ }^{17}$ Simboliza los celos, como explican los versos que siguen; el color figuró antes en la bandera del batallón de caballeros. 
I El amor nasce de celos porque engendra el affición sospecha en el coraçón.

Sjn entrar en el apossiento [sic] después que fueron llegados, aguardaron que las damas llegassen. Y los caualleros con vn callar pensatiuo, y las damas con vn hablar desembuelto, no osando ellos llegar a conuersar con ellas - no porque ellos no tuuiessen manera mas porque no hallauan en su rey voluntad- boluió el dios de amor hazia los caualleros, y con mucho amor mostrando humanidad con ellos, hizo que se pusiessen todos cada qual según quién era, y a todos hablando en ygualdad, porque, avnque entre ellos auía dif $\left[f . x x v i j v^{\circ} a\right]$ ferencia de merescimiento, para con el dios de amor eran todos yguales ${ }^{18}$. Mas después que a todos hizo la honra, a cada qual según su manera, puestos todos donde estar deuían, haziendo el dios de amor más caso de las damas por ser la causa del vencimiento de los caualleros, a ellas con ruego y a los caualleros con mandamiento hizo que se pusiesen todos adonde, puesto él entre ellas y ellos, les hizo este razonamiento:

"Uosotros que soys tan sabios, muy conoscido ternéys que, pues que para las cosas falsas hay razones, que las a de auer para las verdaderas. Y así, yo viendo la causa y razón que todos tenéys para ser heridos en los penssamientos, avnque yo he sido el causador quiero saber cada qual de vosotros de qué golpe ha sido herido. Porque así como en la guerra de armas ay muchas maneras de heridas - vnas de espada, otras de lança, y de otras muchas artes- así en mi batalla, por lo mismo son aquí heridos vnos por la gracia, otros por la hermosura, otros por la conuerssación. Y así auré plazer que me diga cada qual su conoscimiento".

I Responde Salamón.

En todo fue muy cumplida

la dama que yo seruí, pero yo más me vencí por ser muger muy sabida.

I Habla Petrarca.

Pues que toda fue hermosa la dama que yo amé, de toda me contenté.

I Dize Uirgilio.

A mi me hirió mi amiga con la gracia de los ojos que me quitó mil enojos.

${ }^{18}$ Amor no es un monarca democrático: a pesar de algunas diferencias de nacimiento o distinción social, todos son caballeros y por esto merecen igualmente el benigno trato suyo. 


$$
\begin{aligned}
& \text { [f. xxuij } \left.v^{\prime \prime} b\right] \\
& \text { I Habla César. }
\end{aligned}
$$

Fuy vencido de vna dama

por su gracia en la persona

que meresció gran corona.

I Dize Ypólito.

Lo que a mí me captiuó

fue ver $\tan$ gran hermosura

qual de Apeles la pintura ${ }^{19}$.

I Habla Eneas

El lazo en que yo cay

que me dio gloria y passión, fue por la conuersación.

Luego mandó el dios de amor traerles colación, para lo qual vinieron tres, que traya cada qual vn plato grande lleno de lo que los enamorados auían de comer; el vno se llamaua Desseo, y el otro Desorden y el otro Cuydado. Los quales llegaron por mandado de su señor delante de los seys vencidos enamorados, a los quales dándoles de comer les dezían de palabra:

No se dan yeruas en esto, porque no rescibe enojos la boca sino los ojos.

Iua vna toalla muy bien labrada sobre la colación, la qual auían labrado aquellas señoras por quien ellos estaua $n$ vencidos; estaua labrada con sirgo naranjado y verde ${ }^{20}$ y lleuaua vna letra alderredor que dezía:

I A quien sirue de interesse contra honrra del seruido, mandamos ser despedido.

19 Éste no es el Hipólito del Infierno de los enamorados del marqués de Santillana, quien le explicó al autor "[...] Amigo, non curo / de amar nin ser amado, / ca por Júpiter os juro / nunca fuy enamorado" (Canciones y decires, ed. Vicente García de Diego, Espasa-Calpe, Madrid, 1954, p. 16, vv. 217220); por su castidad Diana le apremia con éxitos cinegéticos y amenidades campesinas (p. 19-20, vv. 257-264).

${ }_{20}$ Según el simbolismo de los colores, el verde simboliza la esperanza de lograr conseguir el premio para el amor. El anaranjado puede significar el calor, o sea fuego, de su pasión amorosa, pero Urrea lo emplea de otra manera en Casa de sabiduria: describe una "garita donde estaua Salomón que era alcayde de aquella casa, el qual estaua assentado en vna silla toda pintada de naranjado, que significaua cumplimiento, así como él auía sido en todo muy complido" (f. viij r ${ }^{\circ}$ ). 
Acabadas estas razones, después de auer agradescido los enamorados lo que por ellos se auía hecho, dixeron que les mandasse lo que ellos auían de hazer, porque desseauan seruir para mostrar que la obligación que tenían por lo que auían rescebido; que sabrían pagarla con poner sus personas aparejadas y desseosas para qualquiere mandado que dicho les fuesse. Mas el dios de $\left[f\right.$. xxviij $\left.r^{\prime \prime} a\right]$ amor, no queriendo ya más detenellos porque ya la tarde venía, díxoles que fuessen a sus posadas y que él los daua por libres, y que les quería dar vn consejo, el qual les dixo assí:

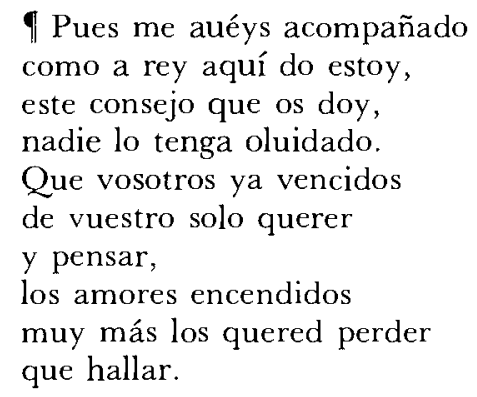

Paresciónos muy bien este consejo al hermitaño y a mí, y viendo que se yuan acordamos de boluernos. Y quando yo me despedía del hermitaño, díxome que pues que el dios de amor auía dado aquel consejo a los enamorados, que affirmando aquél y consejando que huyese del amor que se podía llamar vano, me quería dar otro consejo del amor que yo tuuiesse ${ }^{21}$, diziendo que pues amor quería decir desseo, y el desseo procuraua alcançar que tanto quanto mayor cosa se dessea y procura, tanto es mejor el que el tal desseo tiene. Y para dezirme lo que dessear deuía, hizo este razonamiento que dezía assí:

“Todos naturalmente somos inclinados a vna cosa más que a otras ningunas, y tenemos mayor desseo en aquello que la voluntad se afficiona. Porque la intinción no puede estar dudosa ni repartida, y pues todos procuran lo mejor y ningunos niegan ser esto lo de Dios, yo quiero rogaros que sea éste vuestro amor y que no curéys de seguir aquél que auéys visto. A perdido a los que en esta batalla han entrado, que assí hará a todos los que después viniere $n^{22}$. Mas que sigáys vos aquel

${ }^{21}$ Lo extraño de la despedida de Amor se clarifica aquí en el momento en que Urrea piensa volver a su tema religioso.

${ }^{22}$ En "Fiestas de amor compuestas por don Pedro de Urrea", el poeta inventa otro viaje: después de prometerle que no sufrirá daño alguno, la Muerte le conduce al infierno de amadas y amadores con el propósito de aleccionarle sobre los peligros del amor mundano: "Cupido, aquel dios de amores, / sepas que a todos abrasa; / los más de sus seruidores, / porque siguen sus dulçores, / van después a triste casa. / Mas tú vas para biuir/ y esto te sea escarmiento / que ya buelto deste yr / no quieras ya más siguir / tan dañoso pensamiento"' 
amor de Dios, procurando la saluación del alma, que en esta batalla más cerca tenemos los enemigos, pues que nosotros mismos nos haze[f. xxviij] $\left.r^{\prime \prime} b\right]$ mos daño. ¡O quán pocos son los que se saluan! Los judíos, vemos que se pierden por no llegar a nuestra ley, y los moros por apartarse della. Y de nosotros, ay muchos malos; ved quán pocos se saluan, quántas opiniones avido en el mundo en el tiempo del renegado Mahometo, que por esso pudo él hazer lo que hizo. Y vemos que allá donde fueron todas las opiniones ay muy imica [sic] gente; llámasse la tierra Persia, que quiere decir 'péssima'. Son los más moriscos y la lengua se llama algarauía, que quiere dezir 'vía', 'camino', y 'algala', 'de gala', que es camino vano. Como dezimos de Ytalia que 'yta' quiere dezir 'assí', y 'alia', 'otra cosa'23. Assí vno como otro, que son variables.

"Pero dexadas todas estas cosas, el consejo que yo os quiero dar es que la batalla de vuestro amor sea aquél que se defiende con el mejor escudo, que es la fe; y si de aquella batalla de los amores os podéys quitar, gran parte tenéys de la gloria. De contino trabajad de tener fe, que con aquélla no se puede nadie perder, porque si las malas obras hazen perder las almas, es porque quita $n$ la fe. Mas de contino encomendando vuestra intinción a la trinidad de Dios y a la virginidad de Nuestra Señora, no temáys ninguna cosa. $\mathrm{Y}$ entended esta razón para conoscer las tres personas y la vna escencia de Dios, que es assí como vna fuente, que sale agua della y cae baxo en dos balsas. Y después de salida aquella agua, vna cosa son las balsas y otra la fuente. Mas el agua toda es vna y vn mismo sabor tiene, $\mathrm{d} e$ manera que son tres las partes y vna el agua porque de la fuente no puede salir sino agua que sea tal qual es ella misma. Este es el primor de Dios, ver cómo el Hijo es engendrado y el Espíritu Sancto procediente. Como está en el Credo, Lumbre de lumbre, Dios de Dios. Porque assí como de la candela sale claridad, la qual tomada en otra parte es tan lumbre la vna como la otra, assí de Dios no puede salir sino Dios ser Dios Trinidad. Muy conoscido está, y muchos sabios judíos hablaron de la encarnación de Dios, y por la santa vida que ellos hizieron les dio Dios conoscimiento de su diuinidad y humanidad.

(f. $\mathrm{lj}^{\circ}$ ). Urrea incluye primero las historias de las amadas: "contento y espantado de las mugeriles obras he querido hazer aquí más caso dellas" (prólogo a don Jaime de Luna, f. $1 \mathrm{r}^{\circ}$ ); entre ellas figuran, por ejemplo, "La del rey Yarbas cercada / y Saphos la gran poeta, / Lucrecia la muy nombrada, / y otra gente muy sobrada" (f. lj v ${ }^{\circ}$ ). Explica el título de la poesía en su prólogo: fiestas "porque son las más tristes que hallar mi pensar se pueden, adonde me paresce se deue notar que el amor desordenado y illícito es la cosa que más gente lieua adonde yo cuento" (f. $1 \mathrm{r}^{\circ}$ ).

${ }^{23}$ Urrea demuestra su talento de invención al aclarar la etimología de estos términos. Dirigiéndose al autor de la religión enemiga, el poeta también menciona la lengua suya: "Conosce, Mahoma, que tu algarauía / es lengua sin ley por ser ella tal / rayz de do nasce vn tan crudo mal / que al tercio del mundo el diablo espía" (f. xlix $v^{\circ}$ ). 
" $P u e s$ la virginidad de Nuestra Señora, con mili razones se prueua; la mayor es venir Dios en Ella, que por ser Ella ante que el mundo, no le alcançó el $\left[f . x x v i i j v^{\circ} a\right]$ pecado original. Como algunos que lleuan seta de Philósofos lo dizen, porque si ninguna cosa le faltara, Dios no encarnará en Ella. Pues su virginidad, quán clara está quel cuerpo glorificado puede entrar y salir sin corrupción, como entra el sol por la vedriera sin corrompimiento della. Y como se cría vna avellana de dentro sin que el casco esté rompido, en naturaleza vemos esto y dudámoslo en lo de Dios. El mayor seruicio que se puede hazer a Dios es ser deuoto de su Madre, porque con esto lo somos de Él, pues estuuo Él en Ella. Porque ser denoto solamente de Dios, en qualquier tiempo lo fueron, y el que tiene gran deuoción con Nuestra Señora otorga la venida del Mesías y el cumplimiento de la fe. Y por esto es Dios muy seruido dello.

"Creed siempre estas cosas de la fe y seréys saluo. Y despídome de vos, y Dios os guíe en vuestro camino", me dixo el hermitaño. Yo, con sus sanctas palabras, con mucho amor me despedí dél. Y con el mismo pensamiento que lleuaua me boluí pensando en lo de Dios, tra[f. xxviij $v^{\circ}$ b jbajando todo quanto pude que aquellas palabras que aquel hombre saneto me auía dicho no se me ohndassen. Porque muchas vezes suelen vnas cosas quitar a otras, mayormente las buenas que tienen más virtud que fuerça. Mas yo quedé tan contento de sus buenas razones que procuré, avnque las palabras no tienen cuerpo y entran por el oydo, hazer todo aquello vn ser y guardarle en el coraçón. De manera que, assí como se oye con los oydos se vea con los ojos, porque más enteramente se pueda guardar lo que tanto vale, y con las armas de la fe defender a todo lo que después viniere.

Y assí yo me boluí muy alegre de lo que auía oydo, y triste de lo que auía dexado, paresciéndome que siempre hallaría menos la buena compañía que hauía tenido. Y boluiendo vine siempre pensando en lo de Dios y dexando los tristes amores ${ }^{24}$, teniendo siempre en la memoria el buen consejo que el hermitaño me auía dado.

I Fin de la obra.

${ }^{24}$ Urrea resume la enseñanza del ermitaño en la conseja "Otras suyas estando más deuoto que enamorado": "Huye el amor y el mundo / que el tal plazer es tormento" (f. liiij $\mathrm{v}^{0}$ ); por esto califica de "tristes" los amores que ya piensa rehuir. 